\title{
Levantamento dos Temas TIC e EAD nos Periódicos Qualis
}

\author{
Survey of Issues ICT and EAD \\ in the Qualis Periodics
}

Emanuelly Torres Nunes

Universidade Federal de Alagoas

Ivanderson Pereira da Silva

Universidade Federal de Alagoas

Luis Paulo Leopoldo Mercado

Universidade Federal de Alagoas

\begin{abstract}
Resumo: Nessa pesquisa foi realizado um levantamento bibliográfico dos estudos publicados nos periódicos online, avaliados no Qualis da CAPES e publicados até o ano de 2014, cadastrados nas áreas de Educação e Ensino, e que discutem as temáticas EaD e TIC na Educação. Trata-se de uma investigação de natureza quantitativa que teve por principal objetivo explicitar um panorama dos estudos que enfocam os temas investigados. Neste levantamento foram analisadas 174 revistas, disponíveis online. Nelas foram consultadas as 5.983 unidades de periódicos disponibilizadas nas interfaces online desses periódicos até o primeiro semestre de 2015, momento que foi realizada essa pesquisa. Como resultados foram encontrados 5.613 artigos que discutem EaD ou TIC na Educação. Verificou-se também que a partir do ano de 1995 o número de estudos acerca dos temas desse levantamento cresceu muito timidamente, passando a progredir geometricamente após esse marco temporal.
\end{abstract}

Palavras-chave: Pesquisa de Levantamento. Tecnologias da Informação e da Comunicação. Educação a Distância.

\begin{abstract}
This research was carried out a literature review of studies published in online journals, evaluated at Qualis CAPES and published until 2014, registered in the areas of Education and Training, and discussing thematic distance education and ICT in education. This is an investigation of a quantitative nature which had the main objective to explain an overview of studies that focus on research themes. In this survey were analyzed 174 magazines available online. Them were consulted 5,983 periodicals units available in the online interfaces such periodicals to the first half of 2015, when this survey was conducted. As results were found 5,613 articles that discuss distance education or ICT in education. It was also found that since 1995 the number of studies on the topics of this survey grew very timidly going to progress geometrically after this timeframe.
\end{abstract}

Keywords: Research Survey. Information and Communication Technologies. Distance Education. 


\section{Introdução}

Têm-se observado nos últimos anos uma expansão nos debates científicos sobre o uso das tecnologias da informação e da comunicação (TIC) na Educação e sobre a Educação a Distância (EaD). Isso pode ser verificado a partir de vários aspectos, dentre os quais crescimento do número de publicações científicas com enfoque nesses temas (SILVA e MERCADO, 2015). Tais estudos têm se dedicado a investigar múltiplas dimensões e implicações do uso das TIC na Educação, bem como questões relacionadas a EaD.

Apesar do evidente crescimento do debate sobre TIC e EaD nos círculos de pesquisadores em Educação "faltam estudos que realizem um balanço e encaminhem para a necessidade de um mapeamento que desvende e examine o conhecimento já elaborado e apontem os enfoques, os temas mais pesquisados e as lacunas existentes" (ROMANOWISKY e ENS, 2006, p. 38). Assim, é em face da necessidade de estudos que apontem esse balanço do que já se produziu acerca das TIC na Educação e da EaD bem como de um mapeamento que aponte como tem evoluído esse campo de pesquisa, que se concentram os esforços dessa invetigação.

Nesse estudo, propomos um levantamento bibliográfico cujos objetivos foram explicitar um panorama dos estudos que enfocam os temas investigados e evidenciar o crescimento desse campo de pesquisa até o ano de 2014. O recorte temporal escolhido para se traçar o crescimento do volume de estudos relacionados aos temas desse levantamento foi determinado pelo intervalo compreendido entre o momento em que as revistas selecionadas passaram a disponibilizar suas edições no formato online até as edições que foram disponibilizadas até o primeiro semestre de 2015.

Como alternativa metodológica para identificar tais lacunas, foi possível lançar mão dos estudos do tipo "estado da arte" ou "estado do conhecimento" com abordagem quantitativa. Segundo Ferreira (2002, p. 258), tais pesquisas são definidas como de caráter bibliográfico e

\footnotetext{
são reconhecidas por realizarem uma metodologia de caráter inventariante e descritivo da produção acadêmica e científica sobre o tema que busca investigar, à luz de categorias e facetas que se caracterizam enquanto tais em cada trabalho e no conjunto deles, sob os quais o fenômeno passa a ser analisado.
}

Para Fowler Junior (2011), a pesquisa de levantamento bibliográfico tem por objetivo explicitar dados acerca de aproximações e descolamentos de aspectos da população investigada. Trata-se do "mapeamento da informação produzida e publicada pela humanidade" (GALVÃO, 2010, p. 1). O mapeamento aqui empreendido foi realizado no primeiro semestre de 2015 e tomou como base de dados os periódicos online listados no Qualis da Comissão de Aperfeiçoamento de Pessoal do Nível Superior (CAPES), cadastrados nas áreas de Ensino e Educação e avaliados, à época, com estratos A1, A2, B1, B2, B3, B4, B5 e C.

Para esse levantamento, seguimos a metodologia proposta por Silva e Mercado (2015) que propõem o censo dos estudos que tratam dos temas EaD e TIC na Educação. Esse censo foi realizado consultando cada um dos volumes e números disponibilizados pelas revistas online listadas nessa base. A análise de cada um dos números levantados permitiu a identificação dos estudos relacionados às temáticas a partir da consulta ao título, resumo e palavras-chaves. Os resultados desse movimento investigativo estão dispostos nas próximas sessões. tabelas. 


\title{
20 Qualis e sua metodologia de avaliação
}

A escolha pelos periódicos cadastrados no Qualis da CAPES se deu pelo grau de importância dessa base para o cenário da pesquisa brasileira. Segundo Rocha-e-Silva (2009a, p. 1) o "qualis é definido pela CAPES como uma lista de veículos utilizados para a divulgação da produção intelectual dos programas de pós-graduação stricto sensu (mestrado e doutorado)". Pelo crivo do Qualis passam todos os veículos de divulgação científica diretamente relacionados à pós-graduação stricto sensu brasileira.

Autores como Thomaz, Assad e Moreira (2011, p. 90) entendem que

\begin{abstract}
O Qualis afere a qualidade dos artigos e de outros tipos de produção, a partir da análise da qualidade dos veículos de divulgação, ou seja, periódicos científicos e anais de eventos. Os veículos de divulgação da produção intelectual dos programas de pós-graduação stricto sensu (mestrado e doutorado) são classificados em A1, A2, B1, B2, B3, B4, B5 e C, a partir de valores de corte do fator de impacto do periódico.
\end{abstract}

No debate sobre a avaliação dos veículos de divulgação científica o Fator de Impacto (FI) pode ser considerado para a definição do Qualis do periódico em algumas áreas de avaliação. O FI é um coeficiente que diz respeito à qualidade do periódico avaliado. Periódicos com FI alto estão mais bem qualificados que aqueles com FI baixo. Há de se destacar que o FI é um parâmetro de qualidade internacional, diferente do Qualis que é nacional e dessa forma, é fundamental compreender que nem todas as áreas de avaliação do Qualis percebem o FI da mesma forma no momento de definir os parâmetros de classificação dos periódicos.

Há de se registrar que a forma como a CAPES procede à avaliação do Qualis-Periódicos têm sido duramente questionada por alguns pesquisadores (ROCHA-E-SILVA, 2009a; ROCHA-ESILVA, 2009), mas apesar de entender como relevante essa discussão, nesse estudo, nos limitaremos à descrição de como os periódicos do Qualis são classificados nos estratos $A 1, A 2$, B1, B2, B3, B4, B5 e C, nas áreas de Educação e Ensino.

\section{a) Periódicos da área de Ensino (Área 46)}

A área de Ensino se insere dentro da grande área Multidisciplinar nucleada na antiga área de Ensino de Ciências e Matemática. Foi constituída por decisão do Conselho Superior da CAPES através da portaria no 83/2011. Segundo as diretrizes que orientaram a Avaliação Trienal da área na CAPES, "a área de Ensino é uma área essencialmente de pesquisa translacional, que busca construir pontes, entre conhecimentos acadêmicos, gerados em educação e ensino para sua aplicação em produtos e processos educativos na sociedade" (CAPES, 2013a, p. 1).

Nesse documento, constam os parâmetros de classificação dos periódicos nos diferentes estrados do Qualis além dos critérios para a classificação destes periódicos. Tais critérios podem ser verificados no Quadro 1. 
Quadro 1 - Critérios de avaliação Qualis-Periódicos da Área 46 - Ensino

\begin{tabular}{|c|c|}
\hline Estrato & Descrição \\
\hline $\mathrm{A} 1$ & $\begin{array}{l}\text { Revistas especializadas em ensino/cognição/aprendizagem indexadas nas bases internacionais } \\
\text { ISI/Scopus; } \\
\text { Revistas incluídas na base ERIH classificadas como INT } 1 \text { (educação matemática) } \\
\text { Revistas que contemplem critérios de indução indicados pela área }\end{array}$ \\
\hline $\mathrm{A} 2$ & $\begin{array}{l}\text { Revistas multidisciplinares afins com o ensino indexadas nas bases internacionais ISI/Scopus } \\
\text { Revistas especializadas em ensino/cognição/aprendizagem indexadas no Scielo } \\
\text { Revistas incluídas na base ERIH classificadas como INT } 2 \text { (educação matemática) } \\
\text { Revistas que contemplem critérios de indução indicados pela área }\end{array}$ \\
\hline $\mathrm{B} 1$ & $\begin{array}{l}\text { Revistas especializadas em ensino indexadas nas demais bases internacionais de periódicos } \\
\text { constantes no Portal CAPES (Latindex, Eric, etc.) } \\
\text { Revistas multidisciplinares indexadas no Scielo } \\
\text { Revistas incluídas na base ERIH classificadas como NAT ou W (educação matemática) } \\
\text { Revistas incluídas em outras bases internacionais com justificativa específica encaminhada por } \\
\text { Programa de PG da Área } 46 \\
\text { Revistas com comitê editorial e pelo menos } 3 \text { anos de publicação regular, pelo menos } 2 \text { números } \\
\text { anuais, garantindo ampla diversidade institucional de autores, com pelo menos } 60 \% \text { dos artigos } \\
\text { vinculados a no mínimo } 4 \text { instituições diferentes daquela que edita o periódico } \\
\text { Revistas que contemplem critérios de indução indicados pela Área. }\end{array}$ \\
\hline B2 & $\begin{array}{l}\text { Revistas disciplinares afins com o tema Ensino, indexadas no ISI/SCOPUS/Scielo ou outras } \\
\text { bases, não incluídas nos estratos A1, A2 e B1, valorizando revistas com sítios internet abertos } \\
\text { (Open Access - DIAJ) e/ou com presença no portal da CAPES. } \\
\text { Revistas afins com o tema Ensino, com comitê editorial e publicação regular, pelo menos } 2 \\
\text { números anuais, garantindo ampla diversidade institucional de autores, com pelo menos } 50 \% \\
\text { dos artigos vinculados a no mínimo de } 3 \text { instituições diferentes daquela que edita o periódico. } \\
\text { Revistas editadas nos } 2 \text { últimos anos do triênio por Programas de PG da Área de Ensino }\end{array}$ \\
\hline B3 & $\begin{array}{l}\text { Revistas disciplinares afins com o tema Ensino, indexadas no ISI/SCOPUS/Scielo ou outras bases } \\
\text { latino-americanas e/ou presentes no portal da CAPES não incluídos nos estratos A1, A2, B1 e B2 } \\
\text { Revistas de divulgação científica da SBPC e outras sociedades e instituições científicas } \\
\text { Revistas editadas por Programas de PG de Áreas afins com Ensino }\end{array}$ \\
\hline B4 & $\begin{array}{l}\text { Revistas das demais áreas do conhecimento indexadas no ISI/SCOPUS de modo a valorizar } \\
\text { produção de conhecimento em conteúdos temáticos específicos por equipes que atuam ou } \\
\text { dialogam com a Área de Ensino } \\
\text { Revistas afins com a Área de Ensino não incluídas nos estratos A1, A2, B1, B2 e B3 }\end{array}$ \\
\hline B5 & $\begin{array}{l}\text { Revistas indexadas das demais áreas do conhecimento } \\
\text { Revistas de divulgação em geral afins com a Área de Ensino }\end{array}$ \\
\hline $\mathrm{C}$ & $\overline{\mathrm{as}}$ \\
\hline
\end{tabular}

Fonte: (CAPES, 2013a, p. 38/39)

Esses índices são relevantes, pois a pontuação do Programa de Pós-Graduação (PPG), que permite a ele abrir ou manter os Cursos de Mestrado ou Doutorado, dependem, entre outros critérios, dos somatórios das produções Qualis. A tabela 1, expressa a pontuação que cada artigo publicado numa revista Qualis recebe.

Tabela 1 - Ponderação dos artigos da Área de Ensino segundo o Estrado do Qualis-

\begin{tabular}{lllllllll} 
& A1 & A2 & B1 & B2 & B3 & B4 & B5 & C \\
\hline Pontos & 100 & 85 & 70 & 55 & 40 & 25 & 10 & 0 \\
\hline
\end{tabular}

Fonte: Documento de Área - Ensino (Avaliação Trienal 2013) (CAPES, 2013a, p. 36) 
Nesse sentido, a abertura e a manutenção dos PPG na área de Ensino no Brasil está condicionada a produção Qualis do seu corpo docente. A nota de um PPG, índice que sinaliza a qualidade daquele PPG, está relacionada, entre outros fatores, ao somatório de pontos que cada docente do PPG obtém no Qualis.

\section{b) Periódicos da área de Educação (Área 38)}

Segundo as diretrizes para avaliação trienal da área da Educação, "o qualis-periódicos será produzido pela classificação das revistas tendo por base perfis definidos a partir de critérios comuns a Grande Área de Humanas e dados de indexação em bases nacionais (Scielo e Scielo Educ@) e internacionais quando disponíveis (ISI, Scopus e outras da área de Humanas)" (CAPES, 2013b, p. 17). O quadro 2 apresenta os critérios adotados pela área para classificar os periódicos no Qualis - Educação.

Quadro 2 - Critérios de avaliação Qualis-Periódicos da área da Educação

\begin{tabular}{|c|c|}
\hline Estrato & Definição \\
\hline A1 & $\begin{array}{l}\text { Publicação amplamente reconhecida pela área, seriada, arbitrada e dirigida prioritariamente à } \\
\text { comunidade acadêmico-científica, atendendo a normas editoriais da ABNT ou equivalente (no } \\
\text { exterior). Ter ampla circulação por meio de assinaturas/permutas para a versão impressa, } \\
\text { quando for o caso, e online. Periodicidade mínima de } 3 \text { números anuais e regularidade, com } \\
\text { publicação de todos os números previstos no prazo. Possuir conselho editorial e corpo de } \\
\text { pareceristas formado por pesquisadores nacionais e internacionais de diferentes instituições e } \\
\text { altamente qualificados. Publicar no mínimo } 18 \text { artigos por ano, garantindo ampla diversidade } \\
\text { institucional dos autores: pelo menos } 75 \% \text { de artigos devem estar vinculados a no mínimo } 5 \\
\text { instituições diferentes daquela que edita o periódico. Garantir presença significativa de artigos } \\
\text { de pesquisadores filiados a instituições estrangeiras reconhecidas (acima de dois artigos por } \\
\text { ano). Estar indexado em, pelo menos, } 6 \text { bases de dados, sendo, pelo menos } 3 \text { internacionais. } \\
\text { Constar de bases de indexação, dentre elas o Scielo/Scielo Educa (se brasileiras). }\end{array}$ \\
\hline$A 2$ & $\begin{array}{l}\text { Publicação altamente reconhecida pela área, seriada, arbitrada e dirigida prioritariamente à } \\
\text { comunidade acadêmico-científica, atendendo a normas editoriais da ABNT ou equivalente (no } \\
\text { exterior). Ter ampla circulação por meio de assinaturas/permutas, no caso de revistas apenas } \\
\text { impressas, e estar, preferencialmente, disponível online. Periodicidade mínima de dois } \\
\text { números anuais e regularidade na edição dos números. Possuir conselho editorial e copo de } \\
\text { pareceristas formado por pesquisadores nacionais e internacionais de diferentes instituições e } \\
\text { altamente qualificados. Publicar no mínimo } 18 \text { artigos por ano, garantindo ampla diversidade } \\
\text { institucional dos autores: pelo menos } 75 \% \text { de artigos devem estar vinculados a, no mínimo } 5 \\
\text { instituições diferentes, daquela que edita o periódico. Publicar pelo menos } 2 \text { artigos por ano de } \\
\text { autores vinculados a instituições estrangeiras reconhecidas. Estar indexado em } 5 \text { bases de } \\
\text { dados, sendo pelo menos } 2 \text { internacional. Constar de bases de indexação, dentre elas o } \\
\text { Scielo/Scielo Educa (se brasileiras). }\end{array}$ \\
\hline B1 & $\begin{array}{l}\text { Publicação reconhecida pela área, seriada, arbitrada e dirigida prioritariamente à comunidade } \\
\text { acadêmico-científica, atendendo às normas editoriais da ABNT ou equivalente (no exterior). } \\
\text { Ter circulação nacional por meio de assinaturas/permuta, no caso de revistas apenas } \\
\text { impressas, sendo recomendado que esteja disponível online. Periodicidade mínima de dois } \\
\text { números anuais, regularidade na edição dos números. Possuir conselho editorial e copo de } \\
\text { pareceristas formado por pesquisadores nacionais e internacionais de diferentes instituições e } \\
\text { qualificados. Publicar no mínimo } 14 \text { artigos por ano garantindo ampla diversidade institucional } \\
\text { dos autores: pelo menos } 60 \% \text { de artigos devem estar vinculados a, no mínimo, } 4 \text { instituições } \\
\text { diferentes daquela que edita o periódico. Publicar pelo menos um artigo ao ano de autores } \\
\text { filiados a instituições estrangeiras reconhecidas. Estar indexado em, pelo menos, } 4 \text { bases de } \\
\text { dados nacionais ou internacionais. }\end{array}$ \\
\hline B2 & $\begin{array}{l}\text { Publicação reconhecida pela área, seriada, arbitrada e dirigida prioritariamente à comunidade } \\
\text { acadêmico-científica, atendendo a normas editoriais da ABNT ou equivalente (no exterior). Ter } \\
\text { circulação nacional por meio de assinaturas/permutas, no caso de revistas impressas, sendo } \\
\text { recomendado que esteja disponível online. Periodicidade mínima de } 2 \text { números anuais e } \\
\text { regularidade na edição dos números. Possuir conselho editorial e corpo de pareceristas } \\
\text { formado por pesquisadores nacionais de diferentes instituições e qualificados. Publicar, no } \\
\text { mínimo, } 12 \text { artigos por ano, garantindo diversidade institucional dos autores: pelo menos } 50 \%\end{array}$ \\
\hline
\end{tabular}




\begin{tabular}{|l|l|}
\hline & $\begin{array}{l}\text { de artigos devem estar vinculados a, no mínimo } 3 \text { instituições diferentes daquela que edita o } \\
\text { periódico. Estar indexado em, pelo menos, } 3 \text { bases de dados nacionais ou internacionais. }\end{array}$ \\
\hline B3 & $\begin{array}{l}\text { Publicação seriada, arbitrada e dirigida prioritariamente à comunidade acadêmico-científica, } \\
\text { atendendo a normas editoriais da ABNT ou equivalente (no exterior). Ter circulação nacional } \\
\text { por meio de assinaturas/permutas, no caso de revistas apenas impressas, sendo recomendado } \\
\text { que esteja disponível online. Periodicidade mínima de } 2 \text { números anuais e regularidade na } \\
\text { edição dos números. Possuir conselho editorial e corpo de pareceristas formado por } \\
\text { pesquisadores nacionais de diferentes instituiçães e qualificados. Publicar, no mínimo 12 } \\
\text { artigos por ano, garantindo diversidade institucional dos autores: pelo menos } 40 \% \text { de artigos } \\
\text { devem estar vinculados a, no mínimo, } 3 \text { instituições diferentes daquela que edita o periódico. } \\
\text { Estar indexado em, pelo menos, } 2 \text { bases de dados nacionais ou internacional. }\end{array}$ \\
\hline B4 & $\begin{array}{l}\text { Publicação seriada, arbitrada e dirigida prioritariamente à comunidade acadêmico-científica, na } \\
\text { qual devem constar ISSN, editor responsável, conselho editorial, linha editorial, normas para } \\
\text { submissão de artigos, afiliação institucional dos autores, resumo(s) e descritores. Ter } \\
\text { circulação, no mínimo, regional, periodicidade de } 2 \text { números anuais e regularidade na edição } \\
\text { dos números. Possuir corpo de pareceristas formado por pesquisadores de diferentes } \\
\text { instituições. Publicar, no mínimo, } 12 \text { artigos por ano, garantindo que pelo menos } 50 \% \text { deles } \\
\text { sejam de autores diferentes da instituição que publica o periódico. Estar indexado em pelo } \\
\text { menos } 1 \text { base dados nacional ou internacional. }\end{array}$ \\
\hline $\begin{array}{l}\text { Publicação seriada, arbitrada e dirigida prioritariamente a uma comunidade acadêmico- } \\
\text { científica, na qual devem constar ISSN, editor responsável, conselho editorial, linha editorial, } \\
\text { normas de submissão de artigos, afiliação institucional dos autores, resumo(s) e descritores. } \\
\text { Ter periodicidade de } 2 \text { números anuais e regularidade na edição dos números. Possuir corpo } \\
\text { de pareceristas formado por pesquisadores de mais de uma instituição. Publicar no mínimo 12 } \\
\text { artigos por ano. }\end{array}$ \\
\hline
\end{tabular}

Fonte: Documento de Área - Educação (Avaliação Trienal 2013) (CAPES, 2013b, p. 17)

De forma idêntica à área do Ensino, os PPG da área da Educação pontuam a partir da produção acadêmica do seu corpo docente segundo o mesmo barema descrito na tabela 1. Observa-se que, na classificação do Qualis, independente da área, a publicação em periódicos classificados como A1 é significativamente mais interessante que a publicação em periódicos classificados como B5. Com base nessa lógica, pesquisadores que publicam com frequência em periódicos Qualis $A 1$, ou próximos de A1, tornam-se mais interessantes para os PPG uma vez que dessa pontuação depende sua manutenção.

Nessa investigação têm-se como foco os estudos publicados nos periódicos das áreas de Educação e Ensino e que estão relacionados aos temas TIC e EaD. Para esse mapeamento, foram considerados os periódicos avaliados em todos os estrados: A1, A2, B1, B2, B3, B4 B5 e C a partir dos quais foram acessados todos os números das revistas e consultados os títulos, resumos e palavras-chaves com o objetivo de garimpar as publicações que enfocavam os temas desse levantamento.

\section{TIC e EaD nos periódicos Qualis}

Como fonte de coleta de dados quantitativos foi utilizada a listagem de periódicos que consta no portal Web Qualis. Esse portal disponibiliza em sua interface a relação de periódicos, no âmbito nacional e internacional, avaliados por área de atuação em oito níveis de estrato: A1, A2, B1, B2, B3, B4, B5 e C. Ao analisar as listas dos periódicos avaliados nas áreas de Educação e Ensino, foram encontrados 174 títulos de revistas diretamente relacionadas a essas questões. Essa primeira seleção excluiu periódicos que pesar de terem sido avaliados nessas áreas, não se concentram em veicular estudos diretamente relacionados a elas. Como exemplo desse primeiro mecanismo de seleção é possível apontar a revista "Anais do Museu Paulista" 
classificada na área de Ensino, à época, com o Qualis B2, mas que não está completamente voltada para a divulgação de estudos com temáticas relacionadas à Educação ou ao Ensino.

Após essa primeira seleção foram analisadas cada uma das unidades (unidades correntes ou edições especiais) disponibilizadas nas interfaces online desses periódicos. Nessa segunda etapa, foram desconsideradas as resenhas e entrevistas publicadas. Inicialmente os artigos foram selecionados por título e, quando havia dúvida com relação ao foco do trabalho, era consultado seu respectivo resumo. Esse material levantado foi classificado, segundo a estatística descritiva, em gráficos, tabelas e quadros.

No total foram encontrados 5613 artigos relacionados às áreas de TIC ou EaD, distribuídos conforme a Tabela 2. A última coluna, que se refere à razão artigos encontrados por unidade de periódico (AE/UP), possibilita a visualização da concentração de artigos encontrados em cada periódico. Para obter esse coeficiente foram somados os quantitativos dos artigos levantados e dividido pelo número de unidades da revista em que foram consultados. Nesse sentido, quanto maior for essa razão, maior é a concentração de artigos que enfocam os temas TIC ou EaD por número de revista.

Tabela 2 - Frequência de artigos por periódico

\begin{tabular}{|c|c|c|c|c|c|c|c|}
\hline \multirow[t]{2}{*}{ Nome do Periódico } & \multirow[t]{2}{*}{ Qualis } & \multirow[t]{2}{*}{ ISSN } & \multirow[t]{2}{*}{ IES } & \multirow{2}{*}{$\begin{array}{c}\text { Unidade } \\
\text { de } \\
\text { periódico }\end{array}$} & \multicolumn{2}{|c|}{$\begin{array}{c}\text { Artigos } \\
\text { Encontrados }\end{array}$} & \multirow{2}{*}{$\begin{array}{c}\text { Razão } \\
\text { (AE/UP) }\end{array}$} \\
\hline & & & & & TIC & EaD & \\
\hline A Física na Escola & $\begin{array}{l}\text { B4 - Educação e } \\
\text { B2 - Ensino }\end{array}$ & 19836430 & SBF & 24 & 1 & 0 & 0,0 \\
\hline $\begin{array}{c}\text { Acta Científica (Patos de } \\
\text { Minas) }\end{array}$ & B4 - Educação & 19840918 & FPM & 6 & 1 & 0 & 0,2 \\
\hline Acta Didática Napocensia & B4 - Ensino & 20651430 & $\mathrm{BBU}$ & 25 & 6 & 0 & 0,2 \\
\hline $\begin{array}{l}\text { Acta Scientiarum. } \\
\text { Education } \\
\text { Actualidades }\end{array}$ & B1 - Ensino & 21785201 & UEM & 11 & 2 & 0 & 0,2 \\
\hline $\begin{array}{l}\text { Investigativas en } \\
\text { Educación }\end{array}$ & B3 - Educação & 14094703 & UCR & 44 & 39 & 6 & 0,9 \\
\hline Akrópolis (UNIPAR) & B3- Educação & 15175367 & UNIPAR & 74 & 3 & 3 & 0,0 \\
\hline Alambique (Barcelona) & $\begin{array}{l}\text { B3 - Educação e } \\
\text { B1 - Ensino }\end{array}$ & $\begin{array}{c}20144733 \\
\text { ou } \\
11339837\end{array}$ & GRÂO & 79 & 29 & 2 & 0,4 \\
\hline Alexandria (UFSC) & $\begin{array}{l}\text { B3 - Educação e } \\
\text { B1 - Ensino }\end{array}$ & 19825153 & UFSC & 19 & 2 & 0 & 0,1 \\
\hline $\begin{array}{c}\text { Amazônia - Revista de } \\
\text { Educação em Ciências e } \\
\text { Matemáticas }\end{array}$ & B2 - Ensino & 23175125 & UFPA & 10 & 3 & 2 & 0,3 \\
\hline $\begin{array}{c}\text { American Journal of } \\
\text { Physics }\end{array}$ & A1 - Ensino & 00029505 & AAPT & 864 & 40 & 1 & 0,0 \\
\hline Ângulo (FATEA. Impresso) & B4- Educação & $0101191 X$ & FATEA & 23 & 2 & 2 & 0,1 \\
\hline $\begin{array}{c}\text { Aprendizagem } \\
\text { Significativa em Revista }\end{array}$ & B2 - Ensino & 22383905 & UFRGS & 11 & 1 & 0 & 0,1 \\
\hline Areté (Manaus) & $\begin{array}{l}\text { B3 - Educação e } \\
\text { B2 - Ensino }\end{array}$ & 19847505 & UEA & 15 & 3 & 3 & 0,2 \\
\hline $\begin{array}{l}\text { Atos de Pesquisa em } \\
\text { Educação }\end{array}$ & B1 - Ensino & 18090354 & FURB & 28 & 6 & 5 & 0,2 \\
\hline $\begin{array}{l}\text { BOCC. Biblioteca Online } \\
\text { de Ciências da } \\
\text { Comunicação }\end{array}$ & $\begin{array}{l}\text { B4 - Educação e } \\
\text { B5 - Ensino }\end{array}$ & 16463137 & UBI & 35 & 23 & 4 & 0,7 \\
\hline $\begin{array}{l}\text { Bolema. Boletim de } \\
\text { Educação Matemática }\end{array}$ & A1 - Ensino & $0103636 X$ & UNESP & 54 & 23 & 6 & 0,4 \\
\hline
\end{tabular}




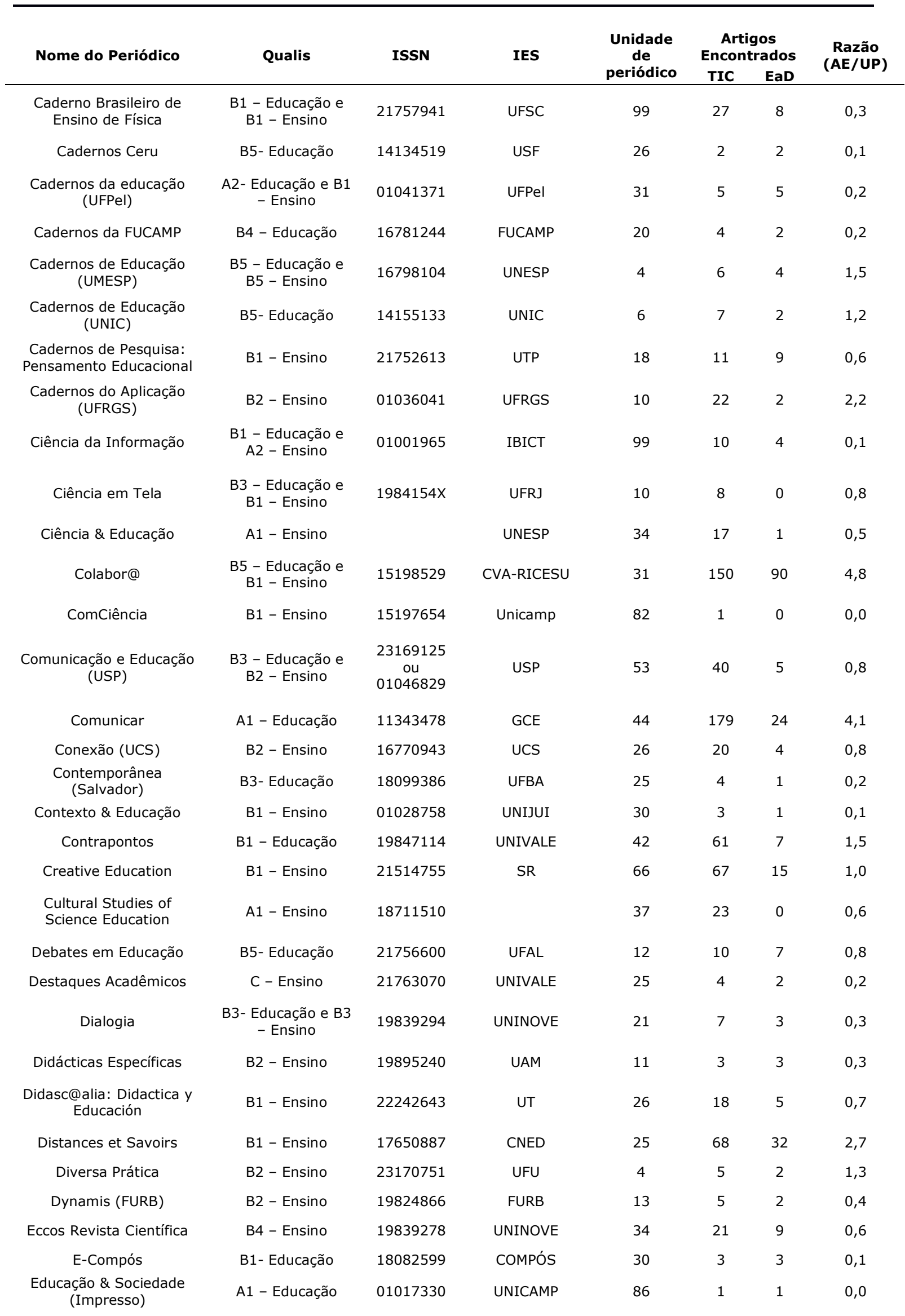




\begin{tabular}{|c|c|c|c|c|c|c|c|}
\hline \multirow{2}{*}{ Nome do Periódico } & \multirow[t]{2}{*}{ Qualis } & \multirow[t]{2}{*}{ ISSN } & \multirow[t]{2}{*}{ IES } & \multirow{2}{*}{$\begin{array}{c}\text { Unidade } \\
\text { de } \\
\text { periódico }\end{array}$} & \multicolumn{2}{|c|}{$\begin{array}{c}\text { Artigos } \\
\text { Encontrados }\end{array}$} & \multirow{2}{*}{$\begin{array}{c}\text { Razão } \\
\text { (AE/UP) }\end{array}$} \\
\hline & & & & & TIC & EaD & \\
\hline Educação \& Tecnologia & $\begin{array}{l}\text { B4 - Educação e } \\
\text { B2 - Ensino }\end{array}$ & 14145057 & CEFET-MG & 6 & 7 & 2 & 1,2 \\
\hline Educação (PUCRS) & $\begin{array}{l}\text { A2 - Educação e } \\
\text { B3 - Ensino }\end{array}$ & 0101495X & PUCRS & 35 & 6 & 3 & 0,2 \\
\hline Educação (Rio Claro) & B2 - Educação & 19818106 & UNESP & 36 & 8 & 2 & 0,2 \\
\hline Educação (Santa Maria) & $\begin{array}{c}\text { B1- Educação e B2 } \\
\text { - Ensino }\end{array}$ & 19846444 & UFSM & 38 & 6 & 2 & 0,2 \\
\hline $\begin{array}{l}\text { Educação e Cultura } \\
\text { Contemporânea }\end{array}$ & $\begin{array}{l}\text { B1 - Educação e } \\
\text { B2 - Ensino }\end{array}$ & 22381279 & UES & 11 & 13 & 5 & 1,2 \\
\hline $\begin{array}{c}\text { Educação e Fronteiras } \\
\text { (UFGD) }\end{array}$ & B3 - Educação & 19826273 & UFGD & 12 & 7 & 4 & 0,6 \\
\hline $\begin{array}{l}\text { Educação e Pesquisa } \\
\text { (USP) }\end{array}$ & A1- Educação & 15179702 & USP & 84 & 10 & 5 & 0,1 \\
\hline Educação e Realidade & $\begin{array}{l}\text { A1 - Educação e } \\
\text { B1 - Ensino }\end{array}$ & 01003143 & UFRGS & 39 & 5 & 1 & 0,1 \\
\hline Educação em Destaque & B2 - Ensino & 19836686 & $\mathrm{CMJF}$ & 7 & 4 & 2 & 0,6 \\
\hline $\begin{array}{c}\text { Educação em Foco (Belo } \\
\text { Horizonte) }\end{array}$ & $\begin{array}{l}\text { B1 - Educação e } \\
\text { B2 - Ensino }\end{array}$ & 15193322 & UEMG & 12 & 6 & 4 & 0,5 \\
\hline $\begin{array}{l}\text { Educação em Foco (Juiz } \\
\text { de Fora) }\end{array}$ & B1 - Educação & 01043293 & UFJF & 23 & 26 & 20 & 1,1 \\
\hline Educação em Perspectiva & B2 - Educação & 21788359 & UFV & 9 & 13 & 6 & 1,4 \\
\hline $\begin{array}{l}\text { Educação em Revista } \\
\text { (Porto Alegre) }\end{array}$ & $\begin{array}{l}\text { B3 - Educação e } \\
\text { B2 - Ensino }\end{array}$ & 18067123 & SINEPE/RS & 18 & 9 & 1 & 0,5 \\
\hline $\begin{array}{c}\text { Educação Física em } \\
\text { Revista }\end{array}$ & B4- Educação & 19836643 & UCB & 20 & 2 & 1 & 0,1 \\
\hline $\begin{array}{c}\text { Educação Matemática } \\
\text { Pesquisa }\end{array}$ & B1 - Ensino & 19833156 & PUC-SP & 30 & 16 & 1 & 0,5 \\
\hline Educação Unisinos & $\begin{array}{c}\text { B1- Educação e B4 } \\
\text { - Ensino }\end{array}$ & $1519387 X$ & UNISINOS & 31 & 5 & 3 & 0,2 \\
\hline $\begin{array}{c}\text { Educação, Formação \& } \\
\text { Tecnologias }\end{array}$ & B3 - Educação & $1646933 x$ & EDUCOM & 15 & 110 & 39 & 7,3 \\
\hline $\begin{array}{c}\text { Educacion y Futuro: } \\
\text { revista de investigacion } \\
\text { aplicada y experiencias } \\
\text { educativas }\end{array}$ & B1 - Ensino & 15765199 & CESDB & 30 & 16 & 4 & 0,5 \\
\hline Educar em Revista & A1 - Educação & 01044060 & UFPR & 65 & 80 & 32 & 1,2 \\
\hline Educativa (Goiânia) & B3 - Ensino & 19837771 & UCG & 17 & 5 & 3 & 0,3 \\
\hline EDUCERE (Mérida) & $\begin{array}{l}\text { B1 - Educação e } \\
\text { A2 - Ensino }\end{array}$ & 13164910 & UNIPAR & 60 & 17 & 6 & 0,3 \\
\hline Educere (Umuarama) & B4- Ensino & 15190099 & UNIPAR & 24 & 8 & 1 & 0,3 \\
\hline Educere et Educare & B3- Educação & 18095208 & UNIOESTE & 19 & 11 & 6 & 0,6 \\
\hline Em Aberto & $\begin{array}{l}\text { B1 - Educação e } \\
\text { B3 - Ensino }\end{array}$ & 01041037 & INEP & 91 & 44 & 26 & 0,5 \\
\hline $\begin{array}{c}\text { EM TEIA: Revista de } \\
\text { Educação Matemática e } \\
\text { Tecnológica } \\
\text { Iberoamericana }\end{array}$ & B2 - Ensino & 21779309 & UFP & 11 & 15 & 6 & 1,4 \\
\hline $\begin{array}{l}\text { Ensaio: Pesquisa em } \\
\text { Educação em Ciências }\end{array}$ & $\begin{array}{c}\text { A2 - Educação e } \\
\text { A2 - Ensino }\end{array}$ & 14152150 & UFMG & 37 & 11 & 0 & 0,3 \\
\hline Enseñanza de las Ciencias & $\begin{array}{l}\text { A1 - Educação e } \\
\text { A1 - Ensino }\end{array}$ & 02124521 & UAB & 14 & 12 & 1 & 0,9 \\
\hline
\end{tabular}




\begin{tabular}{|c|c|c|c|c|c|c|c|}
\hline \multirow{2}{*}{ Nome do Periódico } & \multirow[t]{2}{*}{ Qualis } & \multirow[t]{2}{*}{ ISSN } & \multirow[t]{2}{*}{ IES } & \multirow{2}{*}{$\begin{array}{c}\text { Unidade } \\
\text { de } \\
\text { periódico }\end{array}$} & \multicolumn{2}{|c|}{$\begin{array}{c}\text { Artigos } \\
\text { Encontrados }\end{array}$} & \multirow{2}{*}{$\begin{array}{c}\text { Razão } \\
\text { (AE/UP) }\end{array}$} \\
\hline & & & & & TIC & EaD & \\
\hline $\begin{array}{l}\text { Ensino de Ciências e } \\
\text { Tecnologia em Revista }\end{array}$ & B2 - Ensino & 22374450 & UTFPR & 8 & 11 & 1 & 1,4 \\
\hline Ensino em Revista & $\begin{array}{l}\text { B3 - Educação e } \\
\text { B4 - Ensino }\end{array}$ & 19831730 & UFC & 26 & 12 & 7 & 0,5 \\
\hline Eptic (UFS) & B3 - Educação & 15182487 & UFS & 51 & 12 & 7 & 0,2 \\
\hline $\begin{array}{c}\text { ETD. Educação Temática } \\
\text { Digital }\end{array}$ & $\begin{array}{l}\text { A1 - Educação e } \\
\text { B1 - Ensino }\end{array}$ & 16762592 & UNICAMP & 44 & 92 & 40 & 2,1 \\
\hline $\begin{array}{l}\text { E-tech: Tecnologias para } \\
\text { Competitividade Industrial }\end{array}$ & B4 - Educação & 19831838 & SENAI/SC & 17 & 9 & 7 & 0,5 \\
\hline $\begin{array}{l}\text { European Journal of } \\
\text { Physics }\end{array}$ & A1 - Ensino & 01430807 & DGO & 193 & 91 & 4 & 0,5 \\
\hline $\begin{array}{c}\text { Experiências em Ensino } \\
\text { de Ciências }\end{array}$ & B1 - Ensino & 19822413 & UFMT & 27 & 19 & 4 & 0,7 \\
\hline FACEF Pesquisa & B5 - Educação & 15166503 & UNIFACEF & 48 & 2 & 1 & 0,0 \\
\hline Formação Docente & B3 - Educação & 21764360 & & 7 & 1 & 0 & 0,1 \\
\hline $\begin{array}{l}\text { Horizonte Científico } \\
\text { (Uberlândia) }\end{array}$ & B5 - Educação & 18083064 & UFU & 30 & 6 & 5 & 0,2 \\
\hline IE Comunicaciones & B1 - Educação & 16994574 & ADIE & 44 & 86 & 28 & 2,0 \\
\hline IEEE-RITA & B4 - Educação & 19328540 & IEEE & 21 & 19 & 11 & 0,9 \\
\hline $\begin{array}{c}\text { InCID: Revista de Ciência } \\
\text { da Informação e } \\
\text { Documentação }\end{array}$ & B4 - Educação & 21782075 & USP & 10 & 3 & 1 & 0,3 \\
\hline $\begin{array}{c}\text { Informação \& Informação } \\
\text { (UEL) }\end{array}$ & B4- Educação & 19818920 & UEL & 43 & 6 & 2 & 0,1 \\
\hline Informática na Educação & $\begin{array}{l}\text { B3 - Educação e } \\
\text { B2 - Ensino }\end{array}$ & 19821654 & UFRGS & 32 & 122 & 77 & 3,8 \\
\hline $\begin{array}{c}\text { Instrumento - Revista em } \\
\text { estudo e pesquisa em } \\
\text { educação }\end{array}$ & B3 - Ensino & 19845499 & UFJF & 19 & 13 & 4 & 0,7 \\
\hline Inter-ação (UFG) & B1 - Educação & 19818416 & UFG & 44 & 24 & 12 & 0,5 \\
\hline $\begin{array}{l}\text { InterCom: revista } \\
\text { brasileira de ciências da } \\
\text { comunicação }\end{array}$ & A2 - Educação & 01026453 & INTERCOM & 74 & 6 & 3 & 0,1 \\
\hline Interfaces da Educação & $\begin{array}{l}\text { B4- Educação e } \\
\text { B1- Ensino }\end{array}$ & 21777691 & UEMS & 15 & 4 & 1 & 0,3 \\
\hline Intermeio & B3 - Educação & 14130963 & UFMS & 31 & 4 & 1 & 0,1 \\
\hline $\begin{array}{l}\text { International Journal of } \\
\text { Computers for } \\
\text { Mathematical Learning }\end{array}$ & A1 - Ensino & 13823892 & $\begin{array}{c}\text { Springer } \\
\text { Netherlands }\end{array}$ & 57 & 72 & 8 & 1,3 \\
\hline $\begin{array}{c}\text { International Journal of } \\
\text { Distance Education } \\
\text { Technologies }\end{array}$ & B1 - Ensino & 15393100 & & 49 & 146 & 89 & 3,0 \\
\hline $\begin{array}{c}\text { International Journal of } \\
\text { Education and } \\
\text { Development using } \\
\text { Information and } \\
\text { Communication } \\
\text { Technology }\end{array}$ & A2 - Ensino & 18140556 & Elsevier & 39 & 287 & 50 & 7,4 \\
\hline $\begin{array}{c}\text { International Journal of } \\
\text { Interactive Mobile } \\
\text { Technologies }\end{array}$ & B4 - Ensino & 18657923 & ELSEVIER & 32 & 108 & 32 & 3,4 \\
\hline Intersaberes (Facinter) & B5 - Educação & 18097286 & IBPEX & 18 & 45 & 28 & 2,5 \\
\hline InterScience Place & B5 - Educação & 16799844 & & 31 & 19 & 7 & 0,6 \\
\hline Intersecciones Educativas & B5 - Educação & 07187416 & ULL & 3 & 5 & 1 & 1,7 \\
\hline $\begin{array}{c}\text { Investigações em Ensino } \\
\text { de Ciências }\end{array}$ & $\begin{array}{l}\text { A2- Educação e } \\
\text { A2- Ensino }\end{array}$ & 15188795 & UFRGS & 56 & 7 & 2 & 0,1 \\
\hline Linhas Críticas & B1 - Educação & 19810431 & UnB & 40 & 57 & 18 & 1,4 \\
\hline
\end{tabular}




\begin{tabular}{|c|c|c|c|c|c|c|c|}
\hline \multirow[t]{2}{*}{ Nome do Periódico } & \multirow[t]{2}{*}{ Qualis } & \multirow[t]{2}{*}{ ISSN } & \multirow[t]{2}{*}{ IES } & \multirow{2}{*}{$\begin{array}{c}\text { Unidade } \\
\text { de } \\
\text { periódico }\end{array}$} & \multicolumn{2}{|c|}{$\begin{array}{c}\text { Artigos } \\
\text { Encontrados }\end{array}$} & \multirow{2}{*}{$\begin{array}{c}\text { Razão } \\
\text { (AE/UP) }\end{array}$} \\
\hline & & & & & TIC & EaD & \\
\hline $\begin{array}{l}\text { Literacy Information and } \\
\text { Computer Education } \\
\text { Journal (LICEJ) }\end{array}$ & B1 - Educação & 20402589 & & 20 & 9 & 2 & 0,5 \\
\hline Meta: Avaliação & B3 - Educação & 21752753 & $\begin{array}{l}\text { Fundação } \\
\text { CESGRANRIO }\end{array}$ & 17 & 7 & 6 & 0,4 \\
\hline $\begin{array}{c}\text { Nuances (UNESP } \\
\text { Presidente Prudente) }\end{array}$ & B4 - Educação & 14139855 & UNESP & 28 & 10 & 2 & 0,4 \\
\hline Nucleus (Ituverava) & B5- Educação & 19822278 & $\begin{array}{c}\text { Fundação } \\
\text { educacional de } \\
\text { Ituepava }\end{array}$ & 24 & 4 & 1 & 0,2 \\
\hline Olhar de Professor & $\begin{array}{l}\text { B3 - Educação e } \\
\text { B3 - Ensino }\end{array}$ & 19840187 & UEPG & 26 & 4 & 2 & 0,2 \\
\hline $\begin{array}{l}\text { Páginas Abertas (São } \\
\text { Paulo) }\end{array}$ & B5 - Educação & 14144638 & PAULUS & 17 & 6 & 0 & 0,4 \\
\hline Paidéi@ (Santos) & $\begin{array}{l}\text { B5 - Educação e } \\
\text { B1 - Ensino }\end{array}$ & 19826109 & UNIMES & 18 & 81 & 68 & 4,5 \\
\hline Paidéia & $\begin{array}{l}\text { A1 - Educação e } \\
\text { B2 - Ensino }\end{array}$ & 19824327 & USP & 70 & 2 & 1 & 0,0 \\
\hline Percursos (Florianópolis) & B5- Educação & 19847246 & UDESC & 24 & 3 & 2 & 0,1 \\
\hline Perspectiva (UFSC) & $\begin{array}{l}\text { A2 - Educação e } \\
\text { B1 - Ensino }\end{array}$ & 01025473 & UFSC & 68 & 12 & 8 & 0,2 \\
\hline $\begin{array}{l}\text { Pesquisa em Pós- } \\
\text { Graduação. Série } \\
\text { Educação }\end{array}$ & B5- Educação & 18067846 & UNISANTOS & 4 & 2 & 2 & 0,5 \\
\hline Pesquiseduca & B2 - Ensino & 21771626 & UNISANTOS & 12 & 7 & 4 & 0,6 \\
\hline Pleiade (Uniamérica) & B4 - Educação & 19808666 & UNI-AMERICA & 16 & 3 & 0 & 0,2 \\
\hline $\begin{array}{l}\text { Plurais: Revista } \\
\text { Multidisciplinar da UNEB }\end{array}$ & B5 - Educação & 21775060 & UNEB & 4 & 1 & 0 & 0,3 \\
\hline $\begin{array}{c}\text { POIÉSIS - Revista do } \\
\text { Programa de Pós- } \\
\text { Graduação em Educação } \\
\text { (Unisul) }\end{array}$ & B3 - Educação & 21792534 & UNISUL & 18 & 12 & 8 & 0,7 \\
\hline Ponto de Acesso & B3 - Educação & 19816766 & UFBA & 23 & 3 & 1 & 0,1 \\
\hline Práxis Educacional & B3 - Educação & 21782679 & UESB & 17 & 10 & 8 & 0,6 \\
\hline Qualit@s & B4 - Educação & 16774280 & UEPB & 29 & 2 & 1 & 0,1 \\
\hline $\begin{array}{l}\text { RENOTE. Revista Novas } \\
\text { Tecnologias na Educação }\end{array}$ & $\begin{array}{l}\text { B4 - Educação e } \\
\text { B1 - Ensino }\end{array}$ & 16791916 & UFRGS & 29 & 1239 & 339 & 42,7 \\
\hline $\begin{array}{c}\text { Revemat: Revista } \\
\text { Eletrônica de Educação } \\
\text { Matemática }\end{array}$ & B5 - Educação & 19811322 & UFSC & 15 & 9 & 5 & 0,6 \\
\hline $\begin{array}{l}\text { Revista ACB } \\
\text { (Florianópolis) }\end{array}$ & B3 - Educação & 14140594 & $\mathrm{ABCSC}$ & 31 & 11 & 6 & 0,4 \\
\hline Revista ANPOLL & A2- Educação & 19827830 & UNICAMP & 37 & 17 & 8 & 0,5 \\
\hline $\begin{array}{c}\text { Revista Brasileira de } \\
\text { Aprendizagem Aberta e a } \\
\text { Distância }\end{array}$ & B4 - Educação & 18061362 & ABED & 13 & 146 & 134 & 11,2 \\
\hline $\begin{array}{l}\text { Revista Brasileira de } \\
\text { Computação Aplicada }\end{array}$ & B4 - Ensino & 21766649 & UPF & 11 & 12 & 4 & 1,1 \\
\hline $\begin{array}{l}\text { Revista Brasileira de } \\
\text { Ensino de Ciência e } \\
\text { Tecnologia }\end{array}$ & $\begin{array}{l}\text { B3 - Educação e } \\
\text { B1 - Ensino }\end{array}$ & $1982873 x$ & UTFPR & 21 & 35 & 10 & 1,7 \\
\hline $\begin{array}{l}\text { Revista Brasileira de } \\
\text { Estudos Pedagógicos }\end{array}$ & B1 - Ensino & 00347183 & INEP & 91 & 12 & 6 & 0,1 \\
\hline
\end{tabular}




\begin{tabular}{|c|c|c|c|c|c|c|c|}
\hline \multirow[t]{2}{*}{ Nome do Periódico } & \multirow[t]{2}{*}{ Qualis } & \multirow[t]{2}{*}{ ISSN } & \multirow[t]{2}{*}{ IES } & \multirow{2}{*}{$\begin{array}{c}\text { Unidade } \\
\text { de } \\
\text { periódico }\end{array}$} & \multicolumn{2}{|c|}{$\begin{array}{c}\text { Artigos } \\
\text { Encontrados }\end{array}$} & \multirow{2}{*}{$\begin{array}{c}\text { Razão } \\
\text { (AE/UP) }\end{array}$} \\
\hline & & & & & TIC & EaD & \\
\hline $\begin{array}{c}\text { Revista Brasileira de } \\
\text { Informática na Educação }\end{array}$ & $\begin{array}{l}\text { B4 - Educação e } \\
\text { B2 - Ensino }\end{array}$ & 14145685 & SBC & 45 & 284 & 134 & 6,3 \\
\hline $\begin{array}{c}\text { Revista Brasileira de } \\
\text { Pesquisa em Educação em } \\
\text { Ciências }\end{array}$ & $\begin{array}{l}\text { A2 - Educação e } \\
\text { A2 - Ensino }\end{array}$ & 18065104 & USP & 42 & 8 & 3 & 0,2 \\
\hline $\begin{array}{l}\text { Revista Ciência e } \\
\text { Tecnologia }\end{array}$ & B4 - Educação & 16779649 & UNISAL & 17 & 10 & 2 & 0,6 \\
\hline Revista Ciências \& Idéias & B1 - Ensino & 21761477 & IFRJ & 8 & 5 & 1 & 0,6 \\
\hline $\begin{array}{c}\text { Revista Colombiana de } \\
\text { Educación }\end{array}$ & B4 - Educação & 01203916 & UPN & 10 & 10 & 2 & 1,0 \\
\hline $\begin{array}{l}\text { Revista complutense de } \\
\text { educación }\end{array}$ & A2 - Educação & 11302496 & UCM & 52 & 25 & 5 & 0,5 \\
\hline $\begin{array}{c}\text { Revista Contexto \& } \\
\text { Educação }\end{array}$ & B5- Educação & 21791309 & UNIJUI & 31 & 3 & 3 & 0,1 \\
\hline $\begin{array}{l}\text { Revista de Educação } \\
\text { ANEC }\end{array}$ & B3- Educação & 19835280 & UNESC & 7 & 4 & 1 & 0,6 \\
\hline $\begin{array}{c}\text { Revista de Educação do } \\
\text { Vale do São Francisco } \\
\text { (REVASF) }\end{array}$ & B4- Educação & 21778183 & UNIVASF & 7 & 14 & 8 & 2,0 \\
\hline $\begin{array}{l}\text { Revista de Educação } \\
\text { Publica (UFMT) }\end{array}$ & $\begin{array}{l}\text { A2- Educação e } \\
\text { B1- Ensino }\end{array}$ & 01045962 & UFMT & 27 & 2 & 1 & 0,1 \\
\hline $\begin{array}{c}\text { Revista de Educação PUC- } \\
\text { Campinas }\end{array}$ & B2 - Ensino & 15193993 & PUC-Campinas & 38 & 11 & 7 & 0,3 \\
\hline $\begin{array}{l}\text { Revista de Educação, } \\
\text { Ciência e Cultura }\end{array}$ & B5- Educação & 22366377 & Unilasalle & 16 & 6 & 5 & 0,4 \\
\hline $\begin{array}{l}\text { Revista de Estudios y } \\
\text { Experiencias en Educación }\end{array}$ & B3 - Educação & 07176945 & UCSC & 26 & 12 & 5 & 0,5 \\
\hline $\begin{array}{l}\text { Revista de Gestão da } \\
\text { Tecnologia e Sistemas de } \\
\text { Informação }\end{array}$ & B3 - Educação & 18071775 & USP & 31 & 5 & 5 & 0,2 \\
\hline $\begin{array}{c}\text { Revista de Informática } \\
\text { Aplicada }\end{array}$ & B5 - Ensino & 18095585 & USCS & 18 & 53 & 22 & 2,9 \\
\hline $\begin{array}{c}\text { Revista Diálogo } \\
\text { Educacional (PUCPR) }\end{array}$ & $\begin{array}{l}\text { A2 - Educação e } \\
\text { B1 - Ensino }\end{array}$ & 1981416X & PUCPR & 20 & 29 & 22 & 1,5 \\
\hline $\begin{array}{c}\text { Revista e-Curriculum } \\
\text { (PUCSP) }\end{array}$ & $\begin{array}{l}\text { A2 - Educação e } \\
\text { B5 - Ensino }\end{array}$ & 18093876 & PUCSP & 23 & 50 & 18 & 2,2 \\
\hline $\begin{array}{c}\text { Revista EDaPECI: } \\
\text { Educação a Distância e } \\
\text { Práticas Educativas } \\
\text { Comunicacionais e } \\
\text { Interculturais }\end{array}$ & $\begin{array}{l}\text { B4 - Educação e } \\
\text { B3 - Ensino }\end{array}$ & $2176171 X$ & UFS e UFAL & 17 & 133 & 74 & 7,8 \\
\hline $\begin{array}{l}\text { Revista Educação } \\
\text { (Guarulhos) }\end{array}$ & B1 - Ensino & 19806469 & UNG & 18 & 4 & 3 & 0,2 \\
\hline $\begin{array}{c}\text { Revista Educação } \\
\text { (PUCRS) }\end{array}$ & B3 - Ensino & 19812582 & PUCRS & 35 & 4 & 1 & 0,1 \\
\hline $\begin{array}{c}\text { Revista Educação e } \\
\text { Fronteiras }\end{array}$ & B3 - Educação & $2237258 x$ & UFMS & 12 & 8 & 4 & 0,7 \\
\hline $\begin{array}{l}\text { Revista Educacion y } \\
\text { Pedagogía }\end{array}$ & $\begin{array}{l}\text { B4 - Educação e } \\
\text { B2 - Ensino }\end{array}$ & 01217593 & UDEA & 60 & 22 & 1 & 0,4 \\
\hline $\begin{array}{l}\text { Revista Electrónica de } \\
\text { Investigación Educativa }\end{array}$ & A1 - Ensino & 16074041 & UABC & 37 & 24 & 7 & 0,6 \\
\hline $\begin{array}{l}\text { Revista Electrónica de } \\
\text { Investigación en } \\
\text { Educación en Ciencias }\end{array}$ & A2 - Ensino & 18056666 & UNICEN & 17 & 7 & 1 & 0,4 \\
\hline $\begin{array}{l}\text { Revista Electrónica de } \\
\text { Investigación y Docencia }\end{array}$ & $\begin{array}{l}\text { B5 - Educação e } \\
\text { B5 - Ensino }\end{array}$ & 19892446 & UJ & 15 & 15 & 4 & 1,0 \\
\hline $\begin{array}{l}\text { Revista Eletrônica de } \\
\text { Educação }\end{array}$ & $\begin{array}{l}\text { B2 - Educação e } \\
\text { B1 - Ensino }\end{array}$ & 19827199 & UFSCAR & 17 & 37 & 11 & 2,2 \\
\hline
\end{tabular}




\begin{tabular}{|c|c|c|c|c|c|c|c|}
\hline \multirow{2}{*}{ Nome do Periódico } & \multirow[t]{2}{*}{ Qualis } & \multirow[t]{2}{*}{ ISSN } & \multirow[t]{2}{*}{ IES } & \multirow{2}{*}{$\begin{array}{l}\text { Unidade } \\
\text { de } \\
\text { periódico }\end{array}$} & \multicolumn{2}{|c|}{$\begin{array}{c}\text { Artigos } \\
\text { Encontrados }\end{array}$} & \multirow{2}{*}{$\begin{array}{c}\text { Razão } \\
\text { (AE/UP) }\end{array}$} \\
\hline & & & & & TIC & EaD & \\
\hline $\begin{array}{c}\text { Revista Eureka sobre } \\
\text { Enseñanza y Divulgación } \\
\text { de las Ciencias }\end{array}$ & B4 - Educação & $1697011 X$ & UCA & 37 & 14 & 1 & 0,4 \\
\hline $\begin{array}{l}\text { Revista GEINTEC: gestão, } \\
\text { inovação e tecnologias }\end{array}$ & B5 - Ensino & 22370722 & UFS & 17 & 10 & 5 & 0,6 \\
\hline $\begin{array}{c}\text { Revista Iberoamericana } \\
\text { de Tecnologia en } \\
\text { Educación y Educación en } \\
\text { Tecnología }\end{array}$ & B1 - Ensino & 18509959 & UNCI & 13 & 58 & 24 & 4,5 \\
\hline $\begin{array}{l}\text { Revista Latinoamericana } \\
\text { de Tecnología Educativa }\end{array}$ & $\begin{array}{l}\text { A2 - Educação e } \\
\text { A2 - Ensino }\end{array}$ & $1695288 X$ & UEX & 26 & 218 & 47 & 8,4 \\
\hline $\begin{array}{l}\text { Revista Lusófona de } \\
\text { Educação }\end{array}$ & $\begin{array}{l}\text { A1 - Educação e } \\
\text { A1 - Ensino }\end{array}$ & 16457250 & ULHT & 24 & 3 & 1 & 0,1 \\
\hline Revista NUPEM & B2 - Educação & 21767912 & UEPR & 11 & 3 & 3 & 0,3 \\
\hline Revista Pedagógica & B4 - Educação & 19841566 & UFG & 12 & 4 & 1 & 0,3 \\
\hline Revista Teias & $\begin{array}{c}\text { B1 - Educação e C } \\
\text { - Ensino }\end{array}$ & 19820305 & UERJ & 35 & 29 & 6 & 0,8 \\
\hline Revista Udesc Virtu@। & B5 - Educação & 19842066 & UDESC & 4 & 22 & 12 & 5,5 \\
\hline Revista UNIABEU & B4 - Educação & 21795037 & UNIABEU & 21 & 11 & 4 & 0,5 \\
\hline RISTI & B2 - Educação & 16469895 & AISTI & 16 & 9 & 6 & 0,6 \\
\hline Roteiro & B2- Educação & 21776059 & UNOESC & 18 & 4 & 2 & 0,2 \\
\hline Rumores (USP) & B3 - Educação & $1982677 x$ & USP & 16 & 6 & 2 & 0,4 \\
\hline $\begin{array}{l}\text { TECCOGS: Revista Digital } \\
\text { de Tecnologias Cognitivas }\end{array}$ & B3 - Educação & 19843585 & PUCSP & 7 & 6 & 6 & 0,9 \\
\hline $\begin{array}{l}\text { Temas em Educação } \\
\text { (UFPB) }\end{array}$ & B3 - Educação & 01042777 & UFPB & 6 & 3 & 2 & 0,5 \\
\hline Transinformação & B2 - Educação & 01033786 & PUC Campinas & 66 & 9 & 1 & 0,1 \\
\hline Udesc em Ação & B5 - Ensino & 19827778 & UDESC & 9 & 1 & 0 & 0,1 \\
\hline Unoesc \& Ciência & B4 - Educação & 21785864 & UNOESC & 11 & 3 & 0 & 0,3 \\
\hline Total & & & & 5983 & 5613 & 2027 & \\
\hline
\end{tabular}

Fonte: os autores

A partir da exploração dos periódicos encontrados constatou-se a existência de 15 revistas voltadas especificamente para a divulgação de estudos relacionados à $\mathrm{EaD}$ e às TIC, são elas: "Colabor@", "Distances et Savoirs", "Educação, Formação \& Tecnologia", "IE Comunicaciones", "Informação na Educação: Teoria e Prática", "International Journal of Computers for Mathematical Learning", "International Journal of Distance Education Technologies", "International Journal of Education and Development using Information and Communication Technology", "International Journal of Interactive Mobile Technologies", "Paidéi@: Revista Científica de Educação a Distância", "RENOTE: Revista Novas Tecnologias na Educação", "Revista Brasileira de Aprendizagem Aberta e a Distância", "Revista Brasileira de Informática na Educação", "Revista EDaPECI: Educação a Distância e Práticas Educativas comunicacionais e interculturais", e "Revista Latinoamericana de Tecnologia Educativa".

Dos 15 periódicos citados, sete são editados por instituições internacionais, quatro por instituições do estado de São Paulo, quatro por instituições do Rio Grande do Sul e apenas uma, a Revista EDaPECI é editada por duas instituições da região nordeste [Universidade Federal de Sergipe (UFS) e Universidade Federal de Alagas (UFAL)]. Dos 174 periódicos analisados, 131 são editados por instituições brasileiras. O Gráfico 1 permite a visualização da 
participação de cada estado brasileiro na edição dos 131 periódicos das áreas Ensino e Educação cadastrados no Qualis.

Gráfico 1- Periódicos analisados por Estado

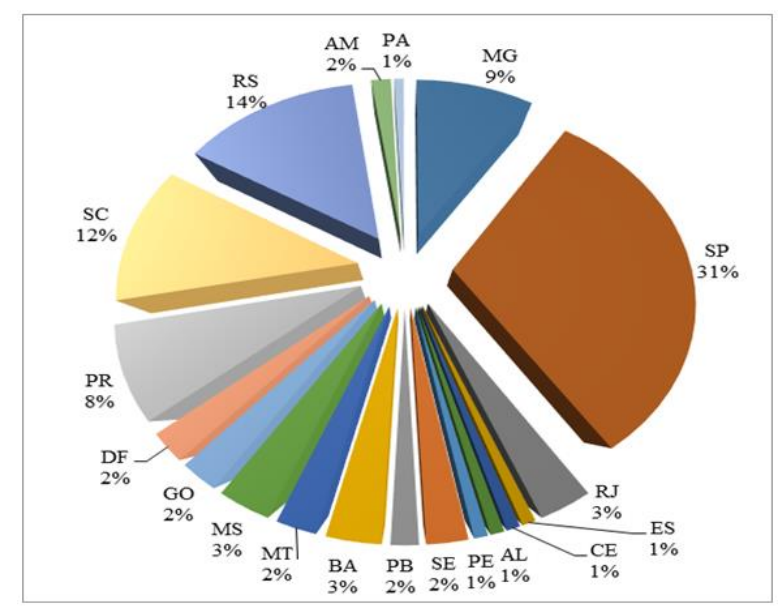

Fonte: Os autores

A partir do Gráfico 1 é possível verificar que São Paulo concentra o maior número de instituições responsáveis pela edição dos periódicos brasileiros analisados. É possível verificar também que dos 131 periódicos brasileiros analisados, 60 são editados por instituições da região Norte; 43 Sudeste; 12 da região Nordeste; 13 da região Centro-oeste; e 3 da região Sul.

A porcentagem do Estado de Alagoas se refere aos periódicos "Debates em Educação" e "Revista EDaPECI: Educação a Distância e Práticas Educativas comunicacionais e interculturais", editados pela UFAL, sendo o primeiro Editado pelo Programa de Pós-graduação em Educação da UFAL e o segundo editado pela UFAL em parceria com a UFS por meio do grupo de pesquisa EDaPECI.

A distribuição temporal dos artigos levantados em função do ano de publicação nos permitiu a composição do gráfico 2 o qual compreende uma janela temporal de 1980 a 2014 . O início do intervalo em 1980 se justifica por terem sido localizados, dentre os periódicos online selecionados, numa edição desse ano, a publicação dos primeiros artigos que enfocavam o tema TIC na Educação.

Gráfico 2: Distribuição de Artigos Publicados por Ano (1980 - 2014)

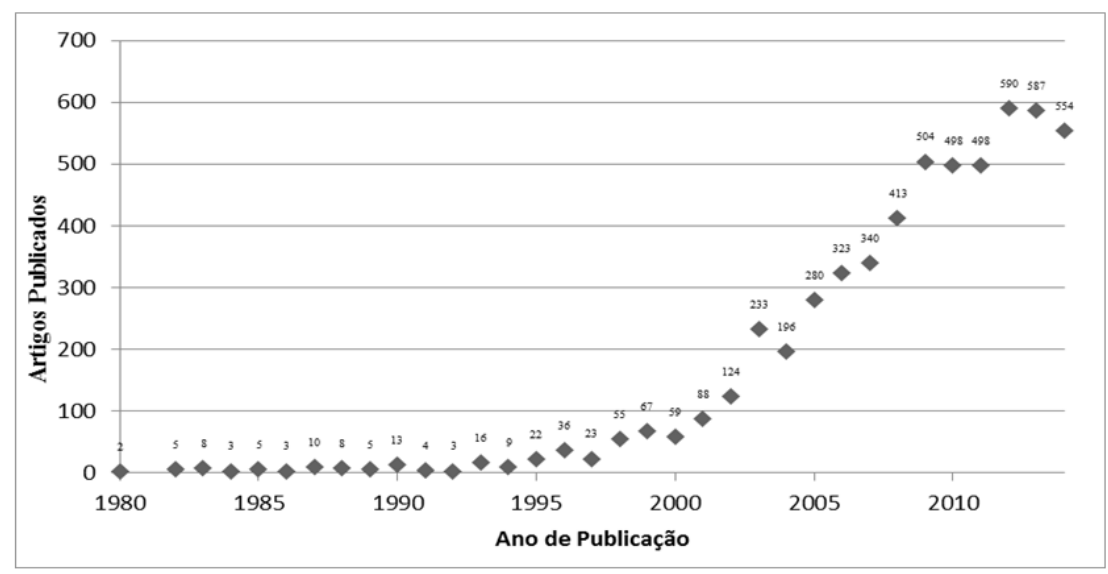

Fonte: Os autores 
Ao verificar o gráfico 2 é possível perceber que apesar das primeiras publicações acerca desse tema, nos periódicos online selecionados, datar de 1980, é a partir de 1995 que se observa um significativo e progressivo crescimento do número absoluto de publicações que enfocavam os temas TIC e EaD. Os pontos próximos a 2014 apresentam uma mudança no comportamento do gráfico porque no período em que o levantamento foi realizado (primeiro semestre de 2015) nem todos os periódicos online consultados tinham disponibilizados os números correspondentes ao ano de 2014.

Tal crescimento se justifica também pelo fato de que, após o ano de 1995, muitos periódicos publicaram dossiês temáticos que enfocavam os temas EaD e TIC na Educação. O quadro 3 lista os dossiês publicados e que estão diretamente relacionados a esses temas.

Quadro 3 - Dossiês Temáticos em TIC na Educação ou EaD

\begin{tabular}{|c|c|c|}
\hline Periódico & Ano & Dossiê Temático \\
\hline $\begin{array}{l}\text { Caderno Brasileiro de } \\
\text { Ensino de Física }\end{array}$ & $\begin{array}{l}2012 \\
2012 \\
2012\end{array}$ & $\begin{array}{l}\text { Dossiê: Ambientes Virtuais de Ensino-Aprendizagem de Física; } \\
\text { Dossiê: Objetivos de Aprendizagem, Recursos Digitais e Virtuais sobre o } \\
\text { Ensino de Física; } \\
\text { Dossiê: Bases teóricas e Metodológicas do Ensino de Física mediadas por } \\
\text { TICs. }\end{array}$ \\
\hline $\begin{array}{c}\text { Cadernos de educação } \\
\text { (UNIC) }\end{array}$ & 2000 & Dossiê: Comunicação: Educação e Informática \\
\hline $\begin{array}{c}\text { Cadernos do Aplicação } \\
\text { (UFRGS) }\end{array}$ & $\begin{array}{l}2008 \\
2011\end{array}$ & $\begin{array}{l}\text { Dossiê: Ensino Médio: novos currículos, metodologias inovadoras e } \\
\text { propostas interdisciplinares; } \\
\text { Dossiê: A Escola em tempos de Internet: o desafio de aliar tecnologia e } \\
\text { educação. }\end{array}$ \\
\hline Colabor@ & $\begin{array}{l}2008 \\
2010 \\
2011 \\
2012\end{array}$ & $\begin{array}{l}\text { Dossiê: Trajetórias Institucionais em EAD; } \\
\text { Dossiê: Redes Sociais; } \\
\text { Dossiê: Qualidade e Gestão na Educação a Distância - Experiências das } \\
\text { Instituições da RICESU; } \\
\text { Dossiê: Redes Sociais e Educação - Desafios Contemporâneos. }\end{array}$ \\
\hline Comunicar & $\begin{array}{l}2009 \\
2012 \\
2012 \\
2014\end{array}$ & $\begin{array}{l}\text { Dossiê: Nuevas formas de comunicación de cibermedios y médios } \\
\text { móveis; } \\
\text { Dossiê: Alfabetização mediática en contextos múltiples; } \\
\text { Dossiê: La formación de profesores em educación en médios; } \\
\text { Dossiê: ¿La revolución de la enseñanza? }\end{array}$ \\
\hline Conexão & 2013 & Dossiê: Comunicação, educação e tecnologias. \\
\hline Contrapontos & $\begin{array}{l}2001 \\
2008 \\
2012\end{array}$ & $\begin{array}{l}\text { Dossiê: Especial Mídia e Novas Tecnologias; } \\
\text { Dossiê: Especial Tecnologia e Inovação Pedagógica; } \\
\text { Dossiê: Aprendizagem, Tecnologias e Conhecimento. }\end{array}$ \\
\hline
\end{tabular}




\begin{tabular}{|c|c|c|}
\hline Periódico & Ano & Dossiê Temático \\
\hline Creative Education & $\begin{array}{l}2013 \\
2014 \\
2014 \\
2014\end{array}$ & $\begin{array}{l}\text { Dossiê: Education and Technology in Developing Countries; } \\
\text { Dossiê: Virtual Learning Environment; } \\
\text { Dossiê: Adoption and Use of Technology in Education; } \\
\text { Dossiê: Knowledge and Education Technology. }\end{array}$ \\
\hline $\begin{array}{l}\text { Cultural Studies os } \\
\text { Science Education }\end{array}$ & 2012 & $\begin{array}{l}\text { Dossiê: Digital Games and learning in science: a sociocultural } \\
\text { perspective. }\end{array}$ \\
\hline $\begin{array}{l}\text { Didasc@alia: Didactica } \\
\text { y Educación }\end{array}$ & 2010 & Dossiê: Nuevas tecnologías para la educación en un nuevo milenio. \\
\hline Eccos Revista Científica & 2008 & Dossiê: Educação a distância: abordagens críticas. \\
\hline $\begin{array}{l}\text { Educação e Fronteiras } \\
\text { On-line }\end{array}$ & 2013 & Dossiê: Educação e Tecnologias. \\
\hline $\begin{array}{l}\text { Educação em Foco } \\
\text { (Belo Horizonte) }\end{array}$ & 2002 & $\begin{array}{l}\text { Dossiê: Educação a Distância; } \\
\text { Dossiê: Educação a Distância:práticas e desafios da formação por meio } \\
\text { de tecnologias. }\end{array}$ \\
\hline $\begin{array}{l}\text { Educação em } \\
\text { Perspectiva }\end{array}$ & 2013 & Dossiê: Do processo e resultados de uma práxis. \\
\hline $\begin{array}{l}\text { Educação, Formação \& } \\
\text { Tecnologia }\end{array}$ & $\begin{array}{l}2009 \\
2010 \\
2010 \\
2010 \\
2011 \\
2011 \\
2011\end{array}$ & $\begin{array}{l}\text { Dossiê: Criatividade e inovação - palavras-chave na aprendizagem no } \\
\text { Século XXI; } \\
\text { Dossiê: Mobilidade, acessibilidade e inclusão; } \\
\text { Dossiê: A Escola e a Agenda Digital Europeia; } \\
\text { Dossiê: A Comunicação Científica e o Acesso Livre ao Conhecimento; } \\
\text { Dossiê: O papel das TIC na Inovação Curricular; } \\
\text { Dossiê: Inovar e partilhar experiências; } \\
\text { Dossiê: As TIC em tempo de revisão curricular. }\end{array}$ \\
\hline Educar em Revista & $\begin{array}{l}2005 \\
2003 \\
2003 \\
2014\end{array}$ & $\begin{array}{l}\text { Dossiê: Mídia e educação: a produção de novos sujeitos e novas } \\
\text { pedagogias; } \\
\text { Dossiê: Educação, Cultura e Tecnologia; } \\
\text { Dossiê: EaD; } \\
\text { Dossiê: Educação a Distância. }\end{array}$ \\
\hline Em Aberto & $\begin{array}{l}1982 \\
1983 \\
1993 \\
1996\end{array}$ & $\begin{array}{l}\text { Dossiê: Tecnologia Educacional; } \\
\text { Dossiê: Educação e Informática; } \\
\text { Dossiê: Diferentes usos do computador na educação; } \\
\text { Dossiê: Educação a distância; }\end{array}$ \\
\hline
\end{tabular}




\begin{tabular}{|c|c|c|}
\hline Periódico & Ano & Dossiê Temático \\
\hline & 2008 & $\begin{array}{l}\text { Dossiê: Integração de mídias nos espaços de aprendizagem; } \\
\text { Dossiê: Educação a distância e formação de professores: problemas, } \\
\text { perspectivas e possibilidades. }\end{array}$ \\
\hline Ensino em Re-vista & 2011 & Dossiê: Educação e Tecnologias. \\
\hline $\begin{array}{l}\text { ETD: Educação } \\
\text { Temática Digital }\end{array}$ & $\begin{array}{l}2009 \\
2011\end{array}$ & $\begin{array}{l}\text { Dossiê: EaD - porque não? } \\
\text { Dossiê: Tecnologias na educação. }\end{array}$ \\
\hline $\begin{array}{l}\text { Informática na } \\
\text { Educação }\end{array}$ & $\begin{array}{l}2001 \\
2002 \\
2003 \\
2004 \\
2006 \\
2007\end{array}$ & $\begin{array}{l}\text { Dossiê: Plataformas para Suporte a Educação a Distância; } \\
\text { Dossiê: Aprendizagem em Ambientes Digitais; } \\
\text { Dossiê: Processos Múltiplos de Interação em Ambientes Virtuais de } \\
\text { Aprendizagem; } \\
\text { Dossiê: Tecnologia Digital na Educação; } \\
\text { Dossiê: Desafios do Virtual para Educação; } \\
\text { Dossiê: Aprendizagens, Interfaces e Tecnologias. }\end{array}$ \\
\hline Inter-ação & $\begin{array}{l}2009 \\
2010 \\
2014\end{array}$ & $\begin{array}{l}\text { Dossiê: Educação e tecnologias; } \\
\text { Dossiê: Formação de professores e educação a distância; } \\
\text { Dossiê: Educação, mídias e cultura. }\end{array}$ \\
\hline $\begin{array}{l}\text { International Journal of } \\
\text { Distance Education } \\
\text { Technologies }\end{array}$ & 2012 & Dossiê: Technology Enhanced Learning. \\
\hline $\begin{array}{l}\text { International Journal of } \\
\text { Education and } \\
\text { Development using } \\
\text { Information and } \\
\text { Communication } \\
\text { Technology }\end{array}$ & $\begin{array}{l}2005 \\
2005 \\
2005 \\
2005 \\
2006 \\
2006 \\
2006 \\
2007 \\
2007 \\
2007 \\
2008 \\
2008 \\
2008 \\
2008\end{array}$ & $\begin{array}{l}\text { Dossiê: Collaboration in using ICT for education \& development; } \\
\text { Dossiê: ICT for education and development in Southern Africa; } \\
\text { Dossiê: ICT for capacity building and knowledge communities; } \\
\text { Dossiê: TICs para o desenvolvimento na Ásia e no Pacífico; } \\
\text { Dossiê: Communication and education using ICT; } \\
\text { Dossiê: Using ICT to empower marginalised groups; } \\
\text { Dossiê: ICT for education and training; } \\
\text { Dossiê: Using ICT to transform education; } \\
\text { Dossiê: Using ICT for rural development; } \\
\text { Dossiê: Participation, collaboration and effective use of ICT; } \\
\text { Dossiê: Using ICT in education for development; } \\
\text { Dossiê: ICT in education and in promoting health; } \\
\text { Dossiê: Planning, policies and strategies for using ICT; } \\
\text { Dossiê: The role of ICT in the classroom, community and nation building; } \\
\text { Dossiê: Potential and challenges in the use and adoption of ICT; }\end{array}$ \\
\hline
\end{tabular}




\begin{tabular}{|c|c|c|}
\hline Periódico & Ano & Dossiê Temático \\
\hline & $\begin{array}{l}2009 \\
2010 \\
2010 \\
2010 \\
2010 \\
2011 \\
2012 \\
2012 \\
2012 \\
2013 \\
2013 \\
2014 \\
2014 \\
2014 \\
\end{array}$ & $\begin{array}{l}\text { Dossiê: ICT in Innovation, Education and Development; } \\
\text { Dossiê: ICT in support of school education; } \\
\text { Dossiê: Impact of ICT on teaching and learning in Asia; } \\
\text { Dossiê: Students, teachers, and ICT for learning; } \\
\text { Dossiê: Evaluation of ICT in education for development; } \\
\text { Dossiê: Surveying perceptions, uses and usage of ICT in education; } \\
\text { Dossiê: ICT integration and effective use in education; } \\
\text { Dossiê: eLearning technologies and resources in the classroom; } \\
\text { Dossiê: ICT and e-learning in secondary and tertiary education; } \\
\text { Dossiê: Integrating technology in teaching; } \\
\text { Dossiê: Critical success factors for ICT usage in learning; } \\
\text { Dossiê: ICT adoption and use in training, learning and counselling; } \\
\text { Dossiê: ICT in education: Reflections, evaluation and design. }\end{array}$ \\
\hline Linhas Críticas & $\begin{array}{l}2003 \\
2007 \\
2009 \\
2009\end{array}$ & $\begin{array}{l}\text { Dossiê: Novas tecnologias na educação; } \\
\text { Dossiê: Educação e Novas Tecnologias; } \\
\text { Dossiê: Formação de Professores; Educação Ambiental; Novas } \\
\text { Tecnologias; } \\
\text { Dossiê: Educação a Distância. }\end{array}$ \\
\hline Nuances & 2014 & Dossiê: Educação Matemática e Tecnologias Digitais. \\
\hline Perspectiva (UFSC) & 2012 & Dossiê: Educação a distância na formação de professores. \\
\hline $\begin{array}{l}\text { Poiésis: Revista do } \\
\text { Programa de Pós- } \\
\text { Graducação em } \\
\text { Educação (Unisul) }\end{array}$ & 2012 & $\begin{array}{l}\text { Dossiê: Ambientes Virtuais: educação e difusão do conhecimento na } \\
\text { sociedade contemporânea. }\end{array}$ \\
\hline Anpoll & 2003 & Dossiê: Linguagem e Web. \\
\hline $\begin{array}{l}\text { Revista Complutense } \\
\text { de Educacíon }\end{array}$ & 2012 & Dossiê: Tecnologías de la información y la comunicación. \\
\hline $\begin{array}{l}\text { Revista de Educação } \\
\text { do Vale do São } \\
\text { Francisco (REVASF) }\end{array}$ & 2014 & Dossiê: Educação a Distância. \\
\hline $\begin{array}{l}\text { Revista Educação e } \\
\text { Fronteiras online }\end{array}$ & 2013 & Dossiê: Educação e Tecnologias \\
\hline $\begin{array}{l}\text { Revista Educacion y } \\
\text { Pedagogía }\end{array}$ & $\begin{array}{l}2002 \\
2012\end{array}$ & $\begin{array}{l}\text { Dossiê: Pedagogía Informática y Nuevas tecnologías; } \\
\text { Dossiê: Educación y cibercultura: campos de estudio, retos y } \\
\text { perspectivas. }\end{array}$ \\
\hline $\begin{array}{l}\text { Revista Eletrônica de } \\
\text { Educação }\end{array}$ & 2013 & Dossiê: Educação e Tecnologia: desafios e possibilidades. \\
\hline
\end{tabular}


Fonte: Os autores

Foram encontrados nas revistas online, selecionadas nesse levantamento, 101 dossiês temáticos enfocando os temas EaD e TIC na Educação. Desses, apenas três foram publicados antes do ano 1995 na revista "Em Aberto". Os outros 98 contribuíram para alavancar o crescimento do número de publicações que enfocavam esses temas no cenário dos veículos de divulgação de pesquisas avaliadas a partir do Qualis.

\section{Considerações finais}

Neste levantamento foram analisadas 5983 unidades de periódicos e levantados 5613 artigos que discutem EaD ou TIC na Educação. Verificou-se que até 1995, o número de estudos acerca dos temas desse levantamento teve um crescimento muito tímido e compreendido entre 13 e 67 estudos por ano. Após o ano de 1995 os periódicos científicos com avaliação Qualis passaram a divulgar um número cada vez maior de trabalhos relacionados a essas temáticas organizando inclusive vários dossiês relacionados às TIC na Educação e à EaD. Em 1995 foram levantados 22 trabalhos relacionados a esses temas e em 2012 já eram 590 as publicações nessa natureza que foram veiculadas pelos periódicos Qualis. Nessa progressão, o número de artigos publicados em periódicos Qualis e que enfocavam os temas TIC na Educação e EaD quase dobra a cada ano. Trata-se de uma área de pesquisa em vertiginoso crescimento.

Para esse fenômeno contribuíram muitos fatores e o detalhamento desses nos remete a um novo estudo. No entanto, já é possível apontar uma hipótese e ao mesmo tempo compartilhar uma preocupação. A hipótese é de que dentre as múltiplas variáveis que contribuíram para consolidar esses campos de pesquisa, destacam-se os largos investimentos em políticas públicas de incentivo ao uso de TIC na Educação e a formação de professores na modalidade a distância, abundantes no Brasil após o ano de 1995. A hipótese que nos remete a um novo estudo é que o cenário político brasileiro desse período, contribuiu significativamente para alavancar as pesquisas em torno das TIC na Educação e da EaD.

Ao mesmo tempo em que essa hipótese de apresenta aos nossos olhos, emerge também a preocupação de que, dado o atual cenário de crise política e econômica no Brasil e os severos cortes no orçamento da Educação, é possível perceber que o fomento aos programas de EaD e de TIC na Educação têm sido drasticamente reduzidos provocando um encolhimento tanto nos cenários formativos quanto nos cenários de pesquisa nesse campo. Essa é uma sugestão para estudos futuros.

Aos/Às interessados/as, disponibilizamos o link com a lista de referências dos artigos levantados: http://migre.me/tWvva

\section{Referências}

CAPES. Documento de Avaliação de Área - Ensino. Avaliação trienal 2013. 2013a. Documento de Avaliação de Área - Educação. Avaliação trienal 2013. 2013b. 
FERREIRA, Norma Sandra de Almeida. As pesquisas denominadas "estado da arte" Educação \& Sociedade, ano XXIII, no 79, p. 257-272, Agosto/2002. Disponível em: http://www.scielo.br/pdf/es/v23n79/10857.pdf Acesso em 17 set 2015.

FOWLER JUNIOR, Floyd, J. Pesquisa de levantamento. 4a ed. Porto Alegre: Penso, 2011.

GALVAO, Maria Cristiane Barbosa. O levantamento bibliográfico e a pesquisa científica. FRANCO, Laércio Joel; PASSOS, Afonso Dinis Costa. (Orgs.). Fundamentos de epidemiologia. 2ed. São Paulo: Manole, 2010, p. 377 - 398. Disponível em: http://www2.eerp.usp.br/Nepien/DisponibilizarArquivos/Levantamento_bibliografico_CristianeGalv.pdf Acesso em 5 mai 2015

ROCHA-E-SILVA, Maurício. Carta Aberta ao Presidente da Capes: o novo Qualis, que não tem nada a ver com ciência do Brasil. Pró-Fono R. Atual. Cient. vol.21 no.4 Barueri oct./dic. 2009. Disponível em: http://www.scielo.br/readcube/epdf.php?doi=10.1590/S0104-56872009000400002\&pid=S010456872009000400002\&pdf_path=pfono/v21n4/02.pdf Acesso em 2 mai 2015

O novo Qualis, ou a tragédia anunciada. Clinics v.64 n.1 São Paulo jan. 2009a. Disponível em: http://www.scielo.br/readcube/epdf.php?doi=10.1590/S1807-59322009000100001\&pid=S180759322009000100001\&pdf_path=clin/v64n1/a01v64n1.pdf Acesso em 2 mai 2015.

ROMANOWSKI, Joana Paulin; ENS, Romilda Teodora. As pesquisas denominadas do tipo "estado da arte" em educação. Diálogo Educação, Curitiba, v. 6, n.19, p.37-50, set./dez. 2006. Disponível em:

http://www2.pucpr.br/reol/pb/index.php/dialogo?dd1=237\&dd99=view\&dd98=pb Acesso em: 17 set 2015 .

SILVA, Ivanderson Pereira da; MERCADO, Luis Paulo L. Levantamento dos temas TIC e EAD na biblioteca virtual Educ@. Cadernos de Pesquisa, v.45 n.158 p.970-988 out./dez. 2015. Disponível em: http://www.scielo.br/pdf/cp/v45n158/1980-5314-cp-45-158-00970.pdf Acesso em 8 fev 2016.

THOMAZ, Petronio Generoso; ASSAD, Renato Samy; MOREIRA, Luiz Felipe P. Uso do Fator de Impacto e do Índice H para Avaliar Pesquisadores e Publicações. Arq Bras Cardiol 2011; 96(2): 90-93. Disponível em: http://www.scielo.br/pdf/abc/v96n2/v96n2a01.pdf Acesso em 2 mai 2015.

Submetido para avaliação em 10 de fevereiro de 2016

Aprovado para publicação em 21 de julho de 2016

\section{Emanuelly Torres Nunes}

Curso de Licenciatura em Física, Universidade Federal de Alagoas, Campus Arapiraca - UFAL, Brasil, emanuelly_torres@hotmail.com

\section{Ivanderson Pereira da Silva}

Programa de Pós-Graduação em Ensino de Ciências e Matemática, Universidade Federal de Alagoas- UFAL. Brasil, ivanderson@gmail.com

\section{Luis Paulo Leopoldo Mercado}

Programa de Pós-Graduação em Educação, Universidade Federal de Alagoas - UFAL, Brasil, luispaulomercado@gmail.com 